\title{
INFORMATION SEARCH BEHAVIOR AND TAX CONSULTANTS' RECOMMENDATION: EXPERIMENTAL EXAMINATION ON THE ROLE OF SOCIAL NORMS
}

\author{
Fauzan MISRA ${ }^{*}$, Slamet SUGIRI ${ }^{2}$, Eko SUWARDI ${ }^{3}$, \\ Ertambang NAHARTYO ${ }^{4}$ \\ ${ }^{1}$ Department of Accounting, Faculty of Economics, Andalas University, Padang, Indonesia \\ 2, 3, ${ }^{4}$ Department of Accounting, Faculty of Economics and Business, \\ Universitas Gadjah Mada, Yogyakarta, Indonesia
}

Received 09 August 2018; accepted 05 September 2019

\begin{abstract}
This-study examines the influence of client preference with respect to information search behavior and subsequent tax recommendation. Prior studies have identified that tax consultants exhibit confirmation bias in their information search processes, which is explained by the theory of motivated reasoning (Kunda, 1990). However, that theory does not take into consideration responses of tax consultant that are attributable to the way clients present their preferences. This study fills the gap by proposing a social norm activation model which can help to foster a better understanding of the nature of the confirmatory behavior. To accomplish this purpose, study participants role-played as advisors on a tax compliance task. The experiment used aweb-based instrument that involved 82 tax professionals. Results showed that tax consultants engaged inlower confirmation bias when they received an explicitly preference statement from their client than those who received an implicit statement. Furthermore, the former tax consultants recommended a more conservative tax position than the latter. These findings underscore the importance of social norm in a professional tax work environment. As a practical contribution, these findings suggest that the beliefs and norms of tax professionals influence the way they do their work.
\end{abstract}

Keywords: tax consultant, client preference, confirmation bias, information search, social norm activation, tax recommendation.

JEL Classification: H26, H32.

\section{Introduction}

A tax consultant plays an important role in a tax system. The optimal recommendation and abiding by professionalism values of tax consultants have an influence on the tax system and program. Simone, Sansing, and Seidman (2008) argue that the mutual benefits from a specified tax program or a taxation system arise from the combination of lower government audit

\footnotetext{
${ }^{\star}$ Corresponding author. E-mail: fauzanmisra@eb.unand.ac.id
} 
cost and lower taxpayer compliance costs. Such costs might be lower because taxpayers are less likely to take tax positions when they have little support and the government is less likely to challenge tax positions that are backed by strong support. By developing a proper tax recommendation, tax consultants play a strategic role of bridging the interests of the two parties.

Prior research has ample evidence that indicates that tax consultants determine the taxpayers' compliance decisions (Stephenson, 2010; Devos, 2012). Furthermore, taxation development leads some countries, including Indonesia, show the tendency of shifting the focus of attention of tax law enforcement toward actions of tax consultants (Hansen \& White, 2012). In Indonesia, the increased monitoring of the accountability of tax consultants is one of the objectives of the Minister of Finance Decree Number 111/2014 concerning tax consultants, which was proposed by the Indonesian government, through the ministry of finance (The Republic of Indonesia, 2014). Enacting the law, according to Mujiaman Harjo, Chief of Indonesian Tax Consultant Association for East Jawa Province, was considered necessary as a response to the rise in demand for tax consulting services over the last few years. Based on data obtained from the website of the Indonesian Tax Consultant Association (IKPI), thereis more 2000 registered tax consultants. These facts imply that to gain a better understanding of the taxpayer's compliance in Indonesia requires knowledge about the way tax consultants provide advice totheir clients. Previous studies (Jiwo \& Zulaikha, 2016; Saputra \& Adam, 2016) on tax consultants in Indonesia tend to focus on individual characteristics, knowledge, and understanding that tax consultant have about their clients. In line with that, this study extends such studies by investigating information search behavior of tax consultants.

Professional accountants are frequently called upon to provide consultation service to their clients. One of the general services accountants provideis tax advice or recommendation ${ }^{1}$. Providing quality advice, tax consultants conduct search for, evaluate the relevancy, and usefulness of, information. Tax Professionals provide valuable service to the clients by reducing the uncertainty related to how a transaction should be reflected on the client's tax return (Philip \& Sansing, 1998; Roberts, 1998; Cloyd \& Spilker, 1999). Tax consultants reduce uncertainty by searching for information and conducting an evaluation of the information to obtain authoritative knowledge about the treatment of a transaction and subsequent tax reporting positionthat is recommended. To accomplish this goal, tax professionals play the role of tax advocates for their clients. Pennington, Schafer, and Pinsker (2017) posit that advocacy attitutes influence the quality and type of evidences collected. Nevertheless, American Institute of Certified Public Accountants [AICPA] $(1995,2008)$ admonishes that advocation role should not ignore objectivity in information search and evaluation processes.

Research on decision making in psychology shows that commitment to or preference for a specific hypothesis (for example a client's preferred position) can induce confirmatory behavior (Andre, 2008). Kunda (1990) asserts that humans tend to experience confirmation bias in searching and evaluating information. This bias can hamper their ability to search for information objectively and subsequently leads to the tendency of making a biased decision. This tendency alsoaffects tax consultants in their provision of services to their clients (Cloyd

\footnotetext{
${ }^{1}$ Data showed that as total revenue of the public accountant offices as a provider of accountant services, on average, gain for about 23\% revenue from the tax consultation (Lee, 2015; Big4, 2015).
} 
\& Spilker, 1999; Wheeler \& Arunachalam, 2008; Cloyd, Spilker, \& Wood, 2012). Thus, as Andre (2008) notes, tax practitioners are not immune to this bias.

Based on previous research, preferencesof clients influence both directly and indirectly influence judgments of accounting professional's (Kadous, Magro, \& Spilker, 2008). The statement implies in an attempt toachieve judicial success, the behavior of a tax professional is influenced by client preferences with respect to the tax position, which leads to a biased judgment. Client preferences have indirect influence on the judgment of the professional through information processing. Specifically, client preferences affect the tax consultant's search for information, leading to confirmation bias. Moreover, by engaging in biased weighing of evidence, make tax professionals unconsciously contribute to making suboptimal decisions (Kahle \& White, 2004). Moreover, the bias also may also motivate tax professionals to inflate their perceived estimation ofthe judicial support to clients' preferencesin the event such positions are challenged by the tax court. This situation can ultimately lead the tax professional to provide recommendations, which are consistent with the clients' preferences but probably improper (overaggressive). Consequently, both the tax professional and the clients may face penalties, liability suit, adverse publicity to tax/ accounting firm, loss of reputation, and loss of client (Hatfield, 2000; Kadous \& Magro, 2001; Cloyd \& Spilker, 1999; Kadous et al., 2008).

We base our investigation on an extension of motivated reasoning theory (Kunda, 1990). Motivated reasoning theory holds that individuals who are committed to directional goals engage in biased reasoning to reach those goals. While a lot of previous research show evidence that supports confirmation bias during the information search process, the process of identifying boundary conditions or mitigating factors, has received little attention. Although the theory of motivated reasoning is able to explainthe existence of confirmatory bias during information search and evaluation, it does not explain the response oftax consultants toward their clients' preferences (both explicitly and implicitly), and how to mitigate such behavior. Biel and Thogersen (2007) argue thatsalient demand and action may activate social norm. Meanwhile, Suddaby, Gendrom, and Lam (2009) contend that professional motivation induces self-perception as a competent professional, independent arbiter and public interest protector. Koch and Salterio (2015) assert the importance of the kind of commitment/motivation (professional vs commercial) that is activated in influencing the occurrence of a confirmatory behavior. In addition, Blay, Gooden, Mellon, and Stevens (2018) recommended that empirical researchers use alternative measures of moral reasoning based on social norm activation. Thus, this research aims to reconcile the abovetwo opposing lines of argument in the literature by incorporating social norm activation model in the formation of confirmation bias. Ditto and Lopez (1992) and Ditto, Munro, Apanovitch, Scepansky, and Lockhart (2003) argue that the influence of directed preference towarda specific behavior should consider how information is searched and processed. Therefore, to gain deeper insight into the influence of information search tax recommendation, it is necessary to scrutinize determinants of information search behavior and the impact on subsequent tax recommendations. Although there is previous research on information search by tax professionals (such as Cloyd \& Spilker, 1999; Kadous et al., 2008) and the confirmatory bias that is attributable to clients' pressure, such studies do not 
consider the role of social norms that are embedded in client preferences that in turn influence tax professional search behavior. This is contrary to previous literature that underscores the strong influence of social norms on Tax complience (Wenzel, 2004).

Kadous et al. (2008) posit thatclients' preferences influence recommendation of tax consultants' both directly and indirectly. This study investigates an indirect effect through the information search process. The main purpose of this study is to gain a better understanding of the nature of confirmatory behaviors, including situational factors that may mitigate such behavior. Specifically, the objective of this research is to investigate whether the client preferences influence information search behavior of tax professionals. Subsequently, this study investigates whether the magnitude of confirmatory behavior impacts the tax consultant's judgment (that is the strength of tax recommendation).

To achieve study objective, study participants played the role of an advisor who conducted a search in a database on judical precedents to find solution for tax client. Information search, according to Kadous et al. (2008) has been an important aspect of tax professionals' responsibilities, and is critical for the quality of recommendations to clients relating to stance to take on tax returns and how to structure transactions. The nature of the client's situation necessitates two possible conditions, one of which turns out to be a strong preference of clients. A web-based instrument monitored the search for, and evaluation of, both the consultans' information search behavior and the subsequent recommendation.

There are two main findings of this study. First, tax consultants who received explicit statements from tax clientsexhibited lower confirmation bias, while those who received implicit statements did not show such behavior. Consequently, tax consultants who receive explicit statements from clients, give relatively more conservative tax recommendation to the former than those who are exposed to implicit clients' statements.

This paper contributes to the existing literature in several ways. Firstly, this research broadens understanding of the effect of clients' preferences on the confirmatory bias behavior of tax consultants by taking into consideration the social norm activation model. In this regard, the contribution of this study lies in demonstrating that the tax consultant is able to overcome confirmation bias if exposed to an explicit preference situation. Second, this research examines the impact of the difference in the way clients state their preferences, which is different from the way previous researchers identified clients' preferences by categorizing them as known and unknown. Contrary to previous studies, this research examines the presentation of clients' preferences to the tax professional into either implicit or explicit. Finally, from a practice standpoint, this study provides deeper insight into the requisite requirements to fulfill the supervision exercise as stipulatedin the codes of ethics and the Professional Standard of Tax Consultants. For the government and the tax consultant association, this research will be beneficial as an input to the policymakers, particularly in relation to monitoring and supervision functions in a tax consultant's office. The following sections present literature review and hypothesis development, research methods, results, discussion, and finally conclusion. 


\section{Literature review and hypothesis development}

\subsection{Tax consultant and confirmatory behavior}

High quality tax service is one of the consultation services that accountant provides (Andre, 2008). In Indonesian setting, as Deborah and Kristiaji (2013) argues, tax consultants' service consists of two primary forms that assist clients to fulfilling their tax obligation, inter alia, preparing tax return for tax reporting, and tax planning consultation. Andre (2008) contends that when the clients ask for advice, the tax consultant faces uncertainty about the kind of treatment that is appropriate for the client's transaction. Faced with such uncertainty, to find solution to the problem, the tax consultant is compelled to conduct research on tax regulation and the past tax court cases that are similar to that of to the client.

Considering the large number of cases on various issues which must be resolved within a limited time the consultant must be selective in sorting out the authoritative evidence to read and use as consideration material in making his tax recommendation. Cloyd and Spilker (1999) emphasize that without adequate understanding of the evidence and information both to support and to oppose the desired tax outcome, tax professional might make bad judgment with the probability that one tax position can be defended before the tax court. Hence, tax professionals need to get a balanced view of the evidence and the information. To that end, tax professionals, should not concentrate on one condition that supports the tax position while ignoring the converse positions.

Research in psychology shows that people tend to have a bias whenever they make a judgment and decision or whenever they try to verify some assumptions. The bias is as result of the tendency of people to limit their attention to theinitial hypothesis, which leads them to prefer evidence or information that supports their belief. Wason (1960) and Nisbett and Ross (1980) refer to this situation as "confirmation bias". Manifestations of confirmation bias include ignoring information that contradicts one's political views as well as overweighting first impressions (Feldman, Goldin, \& Homonoff, 2018).

Consistent with the above general findings in psychology, in accounting, research on tax professional has also found confirmation bias in a variety of tax settings. Previous studies such as Johnson (1993), Cloyd and Spilker (1999), Kadous et al. (2008) and Cloyd et al. (2012) found that in conducting tax research, tax professional tends to focus on information that supports the client's preferred position (positive information) and ignoring information that contradicts that position (negative information), even to the extent to exhibiting improper aggressiveness. The findings suggestthat a tax consultant is not immune to this bias (Andre, 2008). Kadous et al. (2008) assert that confirmation bias is specifically problematic in professional accounting contexts due to the desire to please their clients. This implies that their preferred position is likely to be the client-preferred position, which may be aggressive.

\subsection{Theory of motivated reasoning}

The notion that goals or motives affect the reasoning process has a long and controversial history in the social psychology field (Kunda, 1990). Kunda posits some propositions, which have also been collaborated by other researchers such as motives influence perception (Erde- 
lyi, 1974), attitude (Festinger, 1957) and attribution (Heider, 1958). However, the propositions have faced strong challenge from other psychologists. The strongest criticism stems from Miller and Rose (1975) and Nisbett and Ross (1980) who raise doubts of the possibility that the notion that motivated reasoning can interpreted by the cognitive process, which is a non-motivational construct. They argue that people can reach the self-serving conclusions not because they want to but because such conclusions seem more plausible, given their prior belief and expectations.

Using the motivational term, Kunda (1990) contends that motivation may affect reasoning due to reliance on a biased set of a cognitive process, which includes the strategy for assessing, constructing and evaluating beliefs. Kunda (1990, explains that motivated reasoning phenomena fall into two main categories, inter alia, those that are motivated to arrive at an accurate conclusion and those in which the motive is to reach a particular directional conclusion. The motivation to be accurate will increase the use of beliefs and strategies that are considered to be the best way to reach the desired conclusion. Furthermore, Kunda continues his explanation, that alot of evidence shows that people have the tendency to come up with one particular conclusion that they want to reach, however, their capability to do so is constrained by their ability to build some justification that appears to reasonable enough.

The motivated reasoning occurs when an individual has a desirable conclusion and involvesa decision-making process that induces the motivation to reach that particular conclusion, by reducing ambiguity to a certain acceptable level (Kunda, 1990). Kunda argues that when a decision maker is motivated to reach a particular conclusion, he or she makes serious efforts to construct justification for their desired conclusions that can persuade a dispassionate observer. They can arrive at the conclusion they want only if they find enough evidence to support the desired conclusion and that does not affect thereasonableness constraint-that is, as far as the judgment can still be justified (Kunda, 1990). In situating evidence to support the desirable conclusions, the decision maker tends to believe in a set of cognitive bias processes that include the strategy to assess, to construct and to evaluate the beliefs. This strategy involves the information search, which they consider important to support their desired conclusion, whilst discounting or paying less attention to information that contradicts the conclusion that is not desired. In the same vein, Feldman et al. (2018) argues that the confirmation bias hypothesis posits that an individual generally likes to avoid personally disquieting information and that the strength of the bias in the interpretation of evidence increases with the degree to which the evidence relates directly to a dispute in which one has a personal stake. Decision makers adopt the process without realizing their biased process. In other words, they maintain an illusion of objectivity.

\subsection{Social norm activation model}

Social norms evolve to regulate social life (Biel \& Thogersen, 2007). Specifically, social norms arise is situation where individual action can cause negative side-effects for others (Coleman, 1990) and serve the function of restricting egoistic impulses in the collective outcomes. Social norms imply that people must exhibit a prescribed behavior or not 
manifest an inappropriate behavior (proscribed behavior). Cialdini and Trost (1998) define social norms as rules and standards that are understood by group members, and that guide and/or constrain social behavior without the force of law. Furthermore, social norms often guide the behavior in a specific context, and there is need to active them in many cases (Biel \& Thogersen, 2007).

Some previous literature explains the process of activating social norms. Schwartz (1977) describes the process of activating social norms which involves the triggering of three things: awareness of the environmental problems encountered and relate them to the behavior of the individual concerned; awareness of the relevance of behavior; and awareness of self-efficacy. Besides, Schwartz argues that the activation of norms predicts and explains individual actions or behaviors through an evaluation process that includes moral, social and cost and benefits. Based on Schwartz's (1977) norm activation model that describes altruistic behavior and ecofriendly behavior, the final outcome of model activation can be either be environmentally destructive or eco-friendly behavior.

Meanwhile, Bicchieri's social norm activation model (2006) predicts that a certain decision setting may activate social norms to control opportunistic behavior. According to Bicchieri, the activation of social norms requires contingent conditions or initial conditions and three conditional preference situations. These contingent conditions include the rules of behavior (R), situation (R) and population (P), while conditional preference conditions comprise empirical expectations conditions, normative expectation conditions and normative expectations conditions with sanctions. The Bicchieri model explains the process people use to map the context into specific interpretations, which they afterwards use to shape their beliefs and expectations about the motives and behaviors of others. More specifically, the Bicchieri model implies that the activation of social norms creates relevant beliefs and expectations that subsequently affect individual behavior.

Biel and Thogersen (2007) argue that personal and situational factors trigger the activation of social norms. Personal factors entail the internalization of shared values. Biel and Thogersen point out thatnorms of individuals who are referred to as benevolent are activated when those individuals perceive that their values are facing a threat. Meanwhile, situational factors include the salience of other parties' needs and actions, cost and benefits, information framing, other party behavior and communication.

There is a lot of previous research on the activation of social norms in relation to prosocial behavior, such as attention to environmental issues (i.e Kerr, 1995; Biel \& Thogersen, 2007), and the learning process (Kaklauskas, Zavadskas, \& Budzevičienè, 2009). However, a few previous studies have examined the role and activation of social norms in a business setting. Exceptions include a study by Kirchler, Fehr, and Evans (1996), which examined employee responses to salaries offered by employers, and Davidson and Stevens (2013) that examined the activation of social norms using Bicchieri model in the context of corporate governance, and Saee (2005) that examined societal ethics in a marketing strategies setting. In relation to the taxation context, Wenzel (2004) argues that tax compliance also relates to social norms in the presence of strong social and national identities together with the adherence to norms of taxpaying behavior. 


\subsection{Client's preferences, social norms activation and information search behavior}

Professional accountants provide several services to their clients, including tax service. In providing a quality service, tax professionals must balance the desire to serve and retain the clients as part of their clientele with the requirement to abide by the professional standards and manage the risks associated with making an inappropriate judgment (Nelson, 2003). However, prior research indicates that in resolving client's tax issues, the advocation role of tax professionals tends to force them to search and interpret the information in a consistent way with the desired outcome at the clients' request (Andre, 2008; Bobek, Hageman, \& Hatfield, 2010; Cloyd \& Spilker, 1999, 2000; Kadous et al., 2008; Wheeler \& Arunachalam, 2008). Consequently, recommendations that are made tend to be more skeptical about information that is inconsistent with their preferences than that which is consistent with their preferences (Ditto \& Lopez, 1992). The implication is that decisions that are reached are characterized by preference-inconsistent information in a more error-prone manner (Hales, 2002).

The above findings confirm the argument that tax professionals tend to seek out evidence with outcome-based (a decision-focused search) rather than the facts (an information-focused search) (Cloyd \& Spilker, 1999). By engaging in biased weighting of evidence, tax professionals are unconsciously driven to make suboptimal decisions that in turn induce them to suggest more aggressive tax recommendation to their clients (Kahle \& White, 2004). These findings are consistent with the explanation of the theory of motivated reasoning (Kunda, 1990). Previous literature on motivated reasoning demonstrates that the goal on an individual influences the decision process (Kunda, 1990). The theory of motivated reasoning, however, is not about an individual blindly acting to adopt self-interest-based directional goals. Motivated reasoning theory posits that such adoption of directional goals is subject to a "reasonableness constraint" (Boiney, Kennedy, \& Nye, 1997). When reasonableness constraintcondition is violated, it can lead the decision maker to believe that a "dispassionate observer" would conclude that self-interest had been prioritized by the decision maker beyond other considerations. However, reasonableness constraint isa result of subconscious processing. Kunda (1990) contends that a decisionmaker adopts the process without realizing their biased process.

Biel and Thogersen (2007) posit that both personal and situational factors are relevant for the activation of the social norm. They argue that the social norm is activated if one feels that the values they believe face a threat (personal factor) and when there is salience of need and actions from other actors (situational factors). Explicit preference reflects a salience of need and actions. Besides, Suddaby et al. (2009) notes when professional motivation/commitment is activated during the judgment process, accounting professionals are more sensitive to professional norms that include the desire to be seen as an independent arbiter and a protector of the public interest. Based on insight from Bicchieri's (2006) social norm activation model and recommendation from Blay et al. (2018) to measure moral reasonig based on social norm sensitivity, Blay, Gooden, Mellon, and Stevens (2019) found that social norm activation for honesty and responsibility can improve audit quality. Koch and Salterio (2015) found that if the clients' preferences are declared explicitly, the auditor does not engage in confirmatory biasand as a consequence, the auditor proposes more audit adjustments. Supporting that 
argument, Koch and Salterio (2017) found that perceive excessive client pressure does not compel auditors to exhibit a confirmation bias. On the contrary, such client pressure induces auditors to propose even larger adjustments to client accounting.

The above explanation and findings imply that when tax consultants search for information to solve their clients' tax issues, they focus on information about client reporting positionand other relevant facts and relevant regulations. Clients may state their preference either explicitly or implicitly. It is worth noting that an explicit preference statement reflects the salience need and action, which may activate social norm in an individual. The preposition is that the tax consultants who receiveclient preference implicitly will show higher confirmation bias than those who receive an explicit preference. Since information search behavior can be manifested into some other ways such as the rank of the information item, time spent to review information, and the amount of information saved to support the recommendation, hypothesis $1(\mathrm{H} 1)$ is as follows:

H1: Tax consultant who receives implicit preference statement from theirclients ranks higher, spends longer time, and savesmore information that is consistent with the clients' preference in their information search compared with actions of tax consultantswho receiveexplicit preference.

\subsection{The information search behavior and tax consultants' recommendation}

Cloyd and Spilker (1999) found that subordinates' perception of the evidence that supports the client-preferred tax reporting position has positive relationship with the the subordinates' tax recommendation. Specifically, they found that the tax professional lays more emphasis on the information that supports the position of the clients' expectation (positive case), in comparison with the the information, which supports the alternative position. This is despite the fact that, facts of positive case are irrelevant to the issue facing the clients compared with the negative one. This confirmatory bias, subsequently, leads to an inflated assessment about the probability of the success of clients' judicial claim to the expected position, and to a stronger recommendation for the reporting position that is requested by the clients. This happens to be the case even when client's desired position is not supported legally. Kadous et al. (2008) found that if the tax consultant is exposed to lesser practical risks, the information search tends to be biased in a manner that supports judgments that are consistent with client preferences. Cloyd et al. (2012) finds that confirmation bias measures have positive relationship with the subordinates evidence assessment that supports the reporting position desired by the clients. Thus, the assessment has positive relationship with the strength of tax recommendation the tax consultant offers to clients.

Based on the above findings, recommendations that tax consultant offer to their clients should vary by the nature and type of information search behavior. It is worth noting that information search behavior is categorized into a decision-focused search and an information-focused search. Thus, the type of information search that a tax consultant uses, should influence the strength of tax recommendation he or she gives to the client. A tax consultant with a decision-focused search is more likely to be engaged in a confirmation bias than one who conducts an information-focused search. Consequently, the bias leads consultants to 
make a biased judgment about their support for their client's preferred position, which results into aggressive recommendations. This discussion leads to the following hypothesis:

$\mathrm{H} 2$ : Consultant's information search confirmation bias measures have positive relationship with strength of the consultant's recommendation for the client-preferred tax position.

\section{Research method}

\subsection{Research design}

A controlled laboratory using a 1 x 2 between-subjects was arranged to test the proposed hypotheses. This research manipulates the independent variable (clients' preference statements) into two categories, explicit and implicit. The experiment measures the information search behavior and tax consultant recommendation variables. The experiment was conducted using a web-based instrument. To achieve the validity dan reliability requirement of the research instrument, prior to conducting the experiment, a focused group discussion and a seriesof pilot tests were conducted. The Focus group discussion involved 5 tax professionals and academicians, while the pilot test involved 94 students of Master degree in accounting.

\subsection{Experimental task and procedures}

The task concerns corporate taxation and whether several accounts can be taken as a deduction. The task specifically relates to tax research, that is, collecting and assessing tax evidence in relation to a tax reporting issue. Participants were asked to search for information and provide advice toward the fiscal reconciliation draft preparedby a client. The draft contained some doubtful accounts, which are often the subject of tax auditing or corrections by the tax authority. Cases were developed hypothetically by abstracting from the real cases and the other inputs which are relevant to the study. Information items in the task werebuilt by examining the tax court cases which were obtained from the tax court directory ${ }^{2}$. The cases can be accessed through the official website of the Indonesian Supreme Court. Every case is written in a similar type to that in actual tax court verdicts.

The experiment was conducted using the Internet-based instrument. The software randomly assigns participants to one of the two experimental conditions. The participant gets the access code to log-on to the the instrument websites. Participants obtain information that concerns informed consent, instructions that have to be followed and the memo that explains attributes of the experimental tasks.

From the main menu of the instruments, participants could access the assignment memo, clients' facts, cases databases, and the notebook. Participants were allowed to search for information for 30 minutes. During the searching process, the participant was able to review (1) assessment memo, (2) an overview of indicative factors to determine tax treatment, (3) clients' facts, and (4) databases which contain the 14 tax cases. After finishing their information search, participants were asked to make a tax recommendation. Afterwards, participants were asked to complete the demographic data and answer manipulation check questions. The final session entailed debriefing of the website.

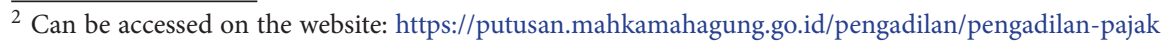




\subsection{Research variables}

The clients' preference, an independent variable is modification of Koch and Salterio (2015) attained by conducting a modification of audit working environment to a tax setting. Client preference was manipulated into two categories, inter alia, implicit and explicit statement. To manipulate client preference, participants received a fictitious meeting note that indicated the respective client's preference. Participants who were assigned to the "explicit" condition were given a note that stressed the importance of accommodating the client's request for two reasons: 1) to support client's business expansion plan; and 2) retain a long term consultation service with the tax professional in broader business scope. For participant who were assigned to the "implicit" condition were given a note that suggested the readiness of the client to accept the best recommendation from their advisor. From the whole research framework, there are two separate dependent variables, inter alia, information search behavior and the tax consultants' recommendation. Themeasured variables (rank, time and save) information search behavior, constituted the dependent variables. In accordance with some researchers (Cloyd et al., 2012; Kadous et al., 2008), these three measures are valid and suitable to determine the tax professionals' information search behavior. Rank refers to the amount of weight for consistent-information toward total weight; while time refers to time spent to prepare tax recommendation for consistent information divided by total time consumed; andsave was measured by comparing information saved for consistent information divided by the total information items provided. The dependent variable, tax recommendation strength, is a modification of Cloyd and Spilker (1999). Cloyd and Spilker (1999) measured tax recommendation by dividing suggested taxable income toward the full compliance condition as directed by tax regulations. This study modified that measure by dividing excess claims on deductible expenses by allowable expenses. Higher level of deductible claim reflects a more aggressive tax recommendation.

\subsection{Participants and manipulation check}

Libby, Bloomfield, and Nelson (2002) suggest that determining proper participants requires researchers to take into consideration the requirements of the experiment. Subjects for this research were Professional tax consultants who work in the Tax Consultant Office (TCO) as well as those who work in the Certified Public Accountant Office (CPA) and Accountant Service Office. CPA participants tax services contribute from $20 \%$ to $25 \%$ (with an average of 23\%) to total CPA firms' revenue come from (Lee, 2015; Big4, 2015).

Participants were recruited by e-mail invitation and by phone. Potential participants' data were obtained from Indonesia Tax Consultants Association and Certified Public Accountant Firm directory. Participants in study had to meet a minimum requirement of having at least one year of work experience. The requirement was used in order to capture subjects' experience in solving clients' tax issues. Data of subjects who didn't meet the requirement were dropped from the analysis. To ensure proper control of this experiment (avoiding maturation), participants were asked to complete the experimental task within an uninterrupted 40-minutes. Manipulation checkwas conducted by asking participants about their experiences during the experiment session. Lastly, all committed participants were exposed to a debriefing. 


\subsection{Data analysis}

Information search behavior was measured using rank, time and save. MANOVA analysis was used to test the first hypothesis. Prior to conducting a MANOVA analysis, testing for statistical assumption requirement wasmade. To test the second hypothesis, which was to examine the relationship between each ofinformation search behavior measure (rank, consist, save) toward the tax consultants' recommendation (Recom), the research used regression analysis.

\section{Research findings and discussion}

\subsection{Participants and manipulation check}

The participants in the study were tax professionals employed in the Tax Consultant Office, Certified Public Accountant Office and Accountant Services Office. Participants completed an online experimental task. They started by opening the task website, and logged in using specified username and password. Out of the 172 usernames distributed, 122 participants had ever logged in to the system. From that number, there were 87 participants, who completed the assignment, and their data were subsequently recorded into the system. Based on the manipulation check test, 5 participants failed to give a proper response, leading to the elimination of their data. The elimination of some participants meant that 82 usable responses remained. Table 1 below depicts the result of the manipulation check:

Table 1. Result of manipulation check

\begin{tabular}{|c|c|c|c|c|c|}
\hline \multicolumn{6}{|c|}{ Client preference } \\
\hline \multicolumn{6}{|c|}{$\begin{array}{l}\text { Categorical manipulation check } \\
\text { Client preference }\end{array}$} \\
\hline & & \multicolumn{2}{|c|}{ Implicit $(\mathrm{N}=45)$} & \multicolumn{2}{|c|}{ Explicit $(\mathrm{N}=42)$} \\
\hline \multicolumn{2}{|c|}{ Amount of correct response } & \multicolumn{2}{|c|}{43} & \multicolumn{2}{|c|}{39} \\
\hline \multicolumn{2}{|c|}{ Percentage of correct response } & \multicolumn{2}{|c|}{95.55} & \multicolumn{2}{|c|}{92.85} \\
\hline \multicolumn{6}{|c|}{$\begin{array}{l}\text { Scale-based manipulation check } \\
\text { Client preference }\end{array}$} \\
\hline & $\begin{array}{l}\text { Implicit } \\
(\mathrm{N}=45)\end{array}$ & $\begin{array}{l}\text { Explicit } \\
(\mathrm{N}=42)\end{array}$ & DF & $\mathrm{t}$ & Sig \\
\hline Mean (DS) & $2.53(0.847)$ & $3.92(0.823)$ & 80 & 7.560 & 0.000 \\
\hline
\end{tabular}

Out of 82 participants, 45 persons were male participants (58.88\%) and the other 37 persons were females $(45.12 \%)$. The education attainment of participants ranged from diploma degree ( 2 persons) to $\mathrm{Ph} . \mathrm{D}$. degree (3 persons). The average working experience of the participants was 76.33 months or 6.4 years, with an average age of 34.61 years old. Based on the affiliation, 40 persons $(48.78 \%)$ of the participants were CPA office employees, 24 persons (29.26\%) were from the Tax Consultant Office; and 18 persons (21.96\%) were employees of the Accountant Services Offices\%). Randomization test showed that there was no difference in participant's demographic characteristics among experimental treatments. Table 2 below presentsthe result of the test. 
Table 2. Result of randomization test

\begin{tabular}{|l|l|c|c|c|c|c|}
\hline \multicolumn{2}{|c|}{ Characteristics } & Sum of Squares & $\mathrm{df}$ & $\begin{array}{c}\text { Mean } \\
\text { Square }\end{array}$ & $\mathrm{F}$ & Sig \\
\hline \multirow{4}{*}{ Age } & Between-groups & 306.273 & 3 & 102.091 & 1.540 & 0.211 \\
\cline { 2 - 7 } & Within-groups & 5169.239 & 78 & 66.272 & & \\
\cline { 2 - 7 } & Total & 5475.512 & 81 & & & \\
\hline \multirow{3}{*}{$\begin{array}{l}\text { Working } \\
\text { Experience }\end{array}$} & Between-groups & 7091.747 & 3 & 2363.916 & 0.506 & 0.679 \\
\cline { 2 - 8 } & Within-groups & 364094.265 & 78 & 4667.875 & & \\
\cline { 2 - 8 } Affiliation & Total & 371186.012 & 81 & & & \\
\hline \multirow{3}{*}{$\begin{array}{l}\text { Education } \\
\text { Level }\end{array}$} & Between-groups & 2.210 & 3 & 0.737 & 1.152 & 0.334 \\
\cline { 2 - 8 } & Within-groups & 49.888 & 78 & 0.640 & & \\
\cline { 2 - 8 } & Total & 52.098 & 81 & & & \\
\cline { 2 - 8 } & Between-goups & 0.717 & 3 & 0.239 & 0.642 & 0.590 \\
\cline { 2 - 8 } & Within-groups & 29.003 & 78 & 0.372 & & \\
\cline { 2 - 7 } & Total & 29.720 & 81 & & & \\
\hline
\end{tabular}

\subsection{Descriptive statistics and the hypothesis testing}

The first hypothesis predicts that the tax consultant who receives implicit preferences from the clients will rank higher, spend more time, and save more information that is consistent with the clients' preferences in their searching for information compared with actions of tax consultants who receive explicit preferences. Reiterating that rankis calculated by adding all the weights of itemsof consistent information divided by the total number weights. The total number of weight of 14 information items was 105 . The measurement of time and number of items saved were operationalized in the same manner as the ranking by comparing time spent and item saved for consistent information toward total time consumed and total information item provided. Participants' responses are shown in the following Table 3 below:

Table 3. Mean and Standard Deviation

\begin{tabular}{|l|l|c|c|c|}
\hline \multirow{4}{*}{ Rank } & \multicolumn{1}{|c|}{ Clients' Preferences } & Mean & Standard Deviation & N \\
\hline \multirow{3}{*}{ Time } & Implicit & 0.557032 & 0.0687517 & 43 \\
\cline { 2 - 5 } & Explicit & 0.466911 & 0.0756083 & 39 \\
\cline { 2 - 5 } & Total & 0.514170 & 0.0847552 & 82 \\
\hline \multirow{3}{*}{ Save } & Implicit & 0.693432 & 0.1362105 & 43 \\
\cline { 2 - 5 } & Explicit & 0.469174 & 0.1482613 & 39 \\
\cline { 2 - 5 } & Total & 0.586773 & 0.1806387 & 82 \\
\cline { 2 - 5 } & Implicit & 0.628971 & 0.1292693 & 39 \\
\cline { 2 - 5 } & Explicit & 0.443270 & 0.0826551 & 82 \\
\hline
\end{tabular}


Furthermore, this studyshows that all the f MANOVA assumption tests (Box's Test of Equality of Covariance Matrices and Levene's test) are fulfilled. Table 4 below depicts the MANOVA model with tax recommendation as the dependent variable:

Table 4. Manova model of the measurement of information search

\begin{tabular}{|c|l|c|c|c|c|}
\hline \multirow{2}{*}{ Source } & $\begin{array}{c}\text { Dependent } \\
\text { Variable }\end{array}$ & Df & Mean Square & F & Sig. \\
\hline \multirow{3}{*}{ Intercept } & Rank & 1 & 21.442 & 4125.926 & 0.000 \\
\cline { 2 - 6 } & Time & 1 & 27.643 & 1369.706 & 0.000 \\
\cline { 2 - 6 } & Save & 1 & 23.513 & 1956.436 & 0.000 \\
\hline \multirow{3}{*}{ Clients' Preferences } & Rank & 1 & 0.166 & 31.961 & 0.000 \\
\cline { 2 - 6 } & Time & 1 & 1.029 & 50.963 & 0.000 \\
\cline { 2 - 6 } & Save & 1 & 0.705 & 58.682 & 0.000 \\
\hline
\end{tabular}

A summary of descriptive statistics of information search behavior appears in Table 3, while the MANOVA model with information search behavior as the dependent variable is depicted in Table 4 . Table 3 shows that there are 43 participants who received implicit preferences, while 39 persons received explicit preferences. That sums up the total number of participants to 82 persons. Based on Table 3, it is evident that consultants who received implicit preferences gave higher score (the total consistent information of the clients' preferences divided by the total amount of rank) at average score of 0.5570 (Standard Deviation $=0.6875$ ). Meanwhile, consultants who received explicit preferences gave an average score of 0.4669 (Standard Deviation $=0.7560$ ). It is thus evident in Table 4 that the differences (main effect of the clients' preference statements toward the ranking measure of confirmatory behavior) is statistically significant $(F=31.961 ; p=0.000)$, therefore, the $\mathrm{H} 1$ supports the rank measure.

Based on the time measure results (Table 3), it is evident that consultants who received an implicit preference statement spent more time to search information, a result that is consistent with client's preferred-tax position in the ratio of 0.6934 (Standard Deviation = 0.1362) in compared with consultants who received explicit preference statement (scoring the rate of 0.4691; Standard Deviation $=0.1482$ ). The differences (the main effect of the clients' preference statements toward the time spent to search and evaluate information) as shown in Table 4 is statistically significant $(F=50.963 ; p=0.000)$, therefore, the H1 for the time measures are supported.

Meanwhile, the measurement of save, which reflects the proportion of information saved between the consistent and inconsistent information, also shows consistent results similar to the other two previous types of information search measures. Table 3 shows that the consultants who received implicit preferences on average saved consistent information on the order of ratio of 0.6289 (Standard Deviation $=0.0826$ ), while consultants who received explicit preferences registered information saved ratio of 0.4432 (Standard Deviation $=0.1482$ ). As can be seen in Table 4, the differences (the main effect of the clients' preference statements toward the amount of information saved) is statistically significant $(\mathrm{F}=58.682 ; p=0.000)$, therefore, the $\mathrm{H} 1$ supports the save measure. 
Based on the above description, it can be concluded that, the three measures of information search behavior show that the consultants who receivedan implicit preference statements from their clients are providing a higher rank, spending more time, and saving more information for information which is consistent with the clients' preferred-tax position rather than the consultants who received an explicit preference statements. This result demonstrates that tax consultant under an implicit situation experienced a decision-focused search. Meanwhile, tax consultant under an explicit situation conducted an information-focused search. These findings indicate that $\mathrm{H} 1$ is supported.

The second hypothesis predicts the effect of information search behaviortoward tax consultants' recommendation. Consultants who are engaged in the higher confirmation bias (a decision-focused search type) will provide a more aggressive recommendation to the clients, rather than the consultants who are not experiencing the confirmation bias or with the lower confirmation bias (an information-focus search type). The second hypothesis (H2) formulated as the higher ranking, the longer time spent, and the more information saved which are consistent with the clients' preferences occur when the recommendation is given is more consistent with the clients' preferences. The resultof regression analysis is presented in Table 5 below:

Table 5. Simple regression result

\begin{tabular}{|c|c|c|c|c|c|c|c|c|c|}
\hline & \multicolumn{3}{|c|}{ RANK } & \multicolumn{3}{|c|}{ TIME } & \multicolumn{3}{|c|}{ SAVE } \\
\hline & $\begin{array}{l}\text { Std. } \\
\text { Beta }\end{array}$ & t-stat & $\begin{array}{c}\text { One- } \\
\text { tailed } \\
\text { p-value }\end{array}$ & $\begin{array}{l}\text { Std. } \\
\text { Beta }\end{array}$ & t-stat & $\begin{array}{c}\text { One- } \\
\text { tailed } \\
\text { p-value }\end{array}$ & $\begin{array}{l}\text { Std. } \\
\text { Beta }\end{array}$ & t-stat & $\begin{array}{c}\text { One- } \\
\text { tailed } \\
\text { p-value }\end{array}$ \\
\hline Intercept & & -2.864 & 0.005 & & 0.026 & 0.980 & & -0.701 & 0.486 \\
\hline Rank & 0.859 & 6.524 & 0.000 & & & & & & \\
\hline Time & & & & 0.609 & 6.862 & 0.000 & & & \\
\hline Save & & & & & & & 0.592 & 6.562 & 0.000 \\
\hline $\mathrm{R} 2$ & \multicolumn{3}{|c|}{0.589} & \multicolumn{3}{|c|}{0.609} & \multicolumn{3}{|c|}{0.592} \\
\hline
\end{tabular}

Table 5 shows that all information search measures (rank, time and save) are statistically significant. The rank measure shows t-stat 6.525 ( $p$-value $=0.000)$, the time measure shows t-stat $6.862(p$-value $=0.000)$ and the save measure has t-stat $6.562(p$-value $=0.000)$. These results suggest that results support $\mathrm{H} 2$.

\section{Discussion}

Tax consultation service requires high quality advice (Andre, 2008). Tax judgment, like other accounting judgments, tends to relate to technical issues within the decision maker's area of occupational specialties for which professional education and training have been received (Wheeler \& Arunachalam, 2008). Considering uncertainties that associated with clients' tax positions, tax professionals have to conduct some research on a myriad of information in a working tax library to identify relevant evidence for a specific issue to support the judgment 
they make. Rose and Wolfe (2000) argues that potential information overloadis one of the main characteristics of the tax professionals' environment.

Given the massive number of issues to handle within limited time available, tax research must be selective in deciding which authoritative source of information to read and use to support the judgment made. Wheeler and Arunachalam (2008) warn of the danger that biased evaluation of tax evidence may lead to skewed assessments of tax issues that tax consultants receive from clients, putting both clients and tax consultants at risk. Besides, biased judgment has adverse impact on the quality of the tax research process. As Cloyd and Spilker (1999) notes, without an understanding of both the authorities that support and those that oppose preferred (or expected) tax outcome, tax professionals may underestimate the possibility that a certain tax position may be challenged in the courts. Thus, to avert such outcomes, the tax professionals should try to obtain a balanced view by taking into consideration evidence and the information that support and oppose the preferred and desired tax position. On the same note, Andre (2008) argues that extant literature on tax jurisprudence underscores the need for tax consultants to take into considerations two elements in conducting research (1) searching both supporting and opposing information and to tax position requested by the clients, and (2) consider the relevancy of the information based on the similarities of the clients' facts and not based on the desired outcome.

Meanwhile, psychology research shows that people may exhibit bias in making judgments, decisions, and verifying assumptions. The bias, induces people to limit their attention tothe initial hypothesis, choosing information and evidence that support their beliefs, consider on only positive cases, according more value to confirmatory examples, and focusing on seeing what they are looking for (Nickerson, 1998). Wason (1960) and Nisbett and Ross (1980) explain this situation as "confirmatory bias". Based on the theory postulated by Kunda (1990) the above situation is referred to as"motivated reasoning". Motivated reasoning occurs when someone has the desired conclusion and engagesin the decision process that makes him/her want to reach that conclusion by giving a certain level of acceptable ambiguity (Kunda, 1990). Andre (2008) argues that based on previous research on confirmation bias, tax professionals are not immune to it either.

On the contrary, Koch and Salterio (2015) found that confirmatory bias does not occur in instances where professional commitment/motivation dominates commercial commitment in making judgments. Koch and Salterio (2015) findingis a reflection ofsocial norm theory dilemma that arises from activation of social norms during the execution of a professional assignment (Kerr, 1995; Biel \& Thogersen, 2007) and argument concerning theactivation of the motivation of a professional accountant within a professional accountant working environment (Suddaby et al., 2009). Biel and Thogersen (2007) argue that social norms forone individual can be activated if one feels that they consider their beliefs are threatened (personal factors) or presence of a salience need and action (situational factors). In accounting and tax setting, the assumption is that when faced with such a condition, the professional accountants ( $\operatorname{tax}$ consultant) will be induced to conduct an introspection and evaluation of their norms and ethics standards, and subsequently will tend to act in accordance with broader public interests.

This study found that the tax professional who faced a salience pressure condition from their client arising from an explicit request, conducted a information-focused search; while a tax consultant who received an implicit preference request engaged in a decision-focused 
search. In other words, tax consultants who received an explicit request engaged in a lower level of confirmation bias than those who received an implicit request. The, above condition reflects an activation of social norm in the tax professional's working environment. This study provides evidence that the perception of high pressure for tax consultant may activate social norm, leading to decisions that are not preferred by clients but in line with laws and regulations. Thus, perception of high pressure from clients to the tax professional to perform in accordance with their desired outcomes, induces social norm activation that counters such pressure by asserting their independence and integrity in reaching professional decisions.

The research finding is consistent with Koch and Salterio (2017) who found that when auditor perceives excessive pressure from clients, confirmatory bias does not occur. Consequently, the auditor conducts information search based on facts (an information-focused search), which leads to suggestions to clients to make more audit adjustments. This studi finding also support Blay et al. (2019) who found that social norm activation for honesty and responsibility can implove audit quality. Thus, the finding underscores the fact that professional behavior of tax professional does not only depend on adhering to explicit professional standards, ethics, guidelines, and laws, but also acting in accordance with social norms that reflect beliefs and values. Faced with explicit preference setting, tax consultants conduct a more balanced search for information, which shows that tax consultants in Indonesia are still cognizant of their norms in providing services to their clients. The implication of the finding is that tax consultants in Indonesia are sensitive to social norm dan professional commitment in making judgment and decision making. The finding that client pressure on tax consultants emanating from aggressive clients paradoxically lowers confirmation bias is important because previous research both within accounting and in the broader judgment and decisionmaking literature indicates that confirmation bias is ubiquitous and difficult to eliminate.

On the other hand, this study shows that the tax consultant who receives implicit preference from clients exhibit stronger confirmation bias in information search processes, which is consistent with of the postulation of the motivated reasoning theory. All confirmatory behavior measures (rank, time and save) showed results that were consistent with theory. Tax consultants who receivedan implicit preference rank higher, spend more time and save more information that is consistent with clients' preferences in comparison with those were exposed to explicit client preferences. The above findings are consistent with Cloyd and Spilker (1999), Kadous et al. (2008) and Cloyd et al. (2012).

Besides, this study also examined whether the indirect effects of client preference on recommendations, which Cloyd and Spilker (1999) observed persist in the current environment. Consistent with prior research (Kadous et al., 2008; Cloyd \& Spilker, 1999), this study also established that professionals who rank higher, spend more time and save more information that supports the client's preferred position also give strong recommendations that aligned with desired tax positions of their clients. Thus, results on implicit preference condition in this study corroborate findings by Cloyd and Spilker (1999) those of with regards to the information search processes and recommendations of accounting professionals that persist in their support of implicit client preferences. Meanwhile, the indirect effect of explicit clients' preferences on recommendations is smaller because professionals face lower confirmation bias to support positions of clients during information search. In this regard, to the activation of the social norm induces tax consultants to exhibit lower confirmation bias (engaged in 
an information-focus search) and provide less-aggressive tax recommendation in comparison with consultants who engage in a higher confirmation bias (conduct decision-focused search). Thus, study findings underscore the fact that biased recommendation to the client's desired outcome only occurs when the tax consultant is engaged in a stronger confirmatory behavior, which is driven by an implicit preference statement.

The above results demonstrate the complexity that relates to client preference effects and highlight the importance of studying decision processes. Considering the importance of information search intax professional work, findings of this research reaffirm the need for knowing the process that tax consultants use to accept clients' preferences and requests and the information search behavior that shapes their response to clients request.

\section{Conclusions}

This study examined the effect of client preference on information search behavior and subsequent tax consultant recommendation. Results of the study showed that the tax consultants who received explicit request statements from clients conducted a more balanced e search for information of authorities that supported and opposed the tax preferred position of their clients. That reflects consultants engaging in a lowerconfirmation bias in their information search dan recommendation preparation processes. These findings are consistent with social norms activation model and literature on accounting professionals. Furthermore, this study also founds that lower confirmation bias in tax professionals is associated with a more conservative tax recommendation to their clients.

While prior researchers considers confirmatory bias pervasive and difficult to eliminate, this study finds that the activation of social norms and professional commitment can mitigate such bias. Study findings underscore the importance of tax professionals to pay attention to their professionalism in providing services to the clients. Consultants who pay attention to values of professionalism evaluate standard norms they cherish in conducting their information search, which informs recommendations they give to clients. Consequently, recommendations that are made to clients are not based on clients' interests but prevailing standards and norms, and by extension public interest.

Findings of this research have some limitations. First, the tax recommendation process is not entirely a job for an individual but involves a group of individuals. This might imply that while some individuals do not engage in confirmation bias, others working on the same team may continue to do so. To that end, future research is needed to examine judgment making process, probability of confirmatory bias behavior in the information search processes and tax recommendation making within a group setting Second, the information searchprocess by participants was limited to the data available in the database used in the experiment. Practically, tax consultants probably have access to an almost unlimited source of information. Last, this study did not consider the effect of the characteristics of tasks (such as task structure and task complexity). The complexity of the task is one of the important factors that characterize the working environment of accountant and tax professionals. In any case, in making tax recommendations for their clients, tax professionals take into consideration the complexity of the task at hand when making tax recommendation. Future research efforts should be geared toward investigating and controlling task characteristics that influence individual's behavior and performance. 


\section{Acknowledgements}

We thanks to Dr. Sumiyana and Prof. Jogiyanto Hartono for their valuable suggestion and initial review to this manuscript.

\section{Author contribution}

Slamt Sugiri, Eko Suwardi and Ertambang Nahartyo are responsible for initial review of the draft. They also contribute to ensure the appropriateness of the theoretical framework and research design.

\section{References}

American Institute of Certified Public Accountants. (1995). AICPA Professional Standards and Code of Professional Conduct. New York. NY: AICPA.

American Institute of Certified Public Accountants. (2008). AICPA Professional Standards. New York, NY: AICPA.

Andre, S. M. (2008). Confirmatory behaviors in tax: exploring how advisors search for and evaluate information. https://doi.org/10.2139/ssrn.1093370

Bicchieri, C. (2006). The grammar of society: the nature and dynamics of social norms. New York, NY: Cambridge University Press. https://doi.org/10.1017/CBO9780511616037

Big4. (2015). An analysis of the 2014 financial performance of the world's largest accounting firms. Retrieved from https://www.scribd.com/document/307356545/The-2014-Big-Four-Firms-Performance-Analysis-Big4-Com-Jan-2015

Blay, A., Gooden, E., Mellon, M., \& Stevens, D. (2018). The usefulness of social norm theory in empirical business ethics research: A review and suggestions for future research. Journal of Business Ethics, 152, 191-206. https://doi.org/10.1007/s10551-016-3286-4

Blay, A. D., Gooden, E. S., Mellon, M. J., \& Stevens, D. E. (2019). Can social norm activation improve audit quality? Evidence from an experimental audit market. Journal of Business Ethics, 156, 513-530. https://doi.org/10.1007/s10551-017-3561-z

Bobek, D. D., Hageman, A. M., \& Hatfield, R. C. (2010). The role of client advocacy in the development of tax professionals' advice. The Journal of the American Taxation Association, 32(1), 25-51. https://doi.org/10.2308/jata.2010.32.1.25

Biel, A., \& Thogersen, J. (2007). Activation of social norms in social dilemmas: A review of the evidence and reflections on the implications for environmental behavior. Journal of Economic Psychology, 28, 93-112. https://doi.org/10.1016/j.joep.2006.03.003

Boiney, L. G., Kennedy, J., \& Nye, P. (1997). Instrumental bias in motivated reasoning: More when more is needed. Organizational Behavior and Human Decision Processes, 72(1), 1-24. https://doi.org/10.1006/obhd.1997.2729

Cloyd, C. B., Spilker, B. C., \& Wood, D. A. (2012). The effect of supervisory advises on tax professionals' information search behavior. Advances in Taxation, 22, 135-158.

https://doi.org/10.1108/S1058-7497(2012)0000020008

Cloyd, C. B., \& Spilker, B. C. (1999). The influence of client preferences on tax professionals' search for judicial precedents, subsequent judgments and recommendations. The Accounting Review, 74(3), 299-322. https://doi.org/10.2308/accr.1999.74.3.299

Coleman, J. (1990). Foundations of social theory. Cambridge, MA: Harvard University Press.

Deborah, \& Kristiaji, B. B. (2013). Menyoal praktik konsultan pajak di Indonesia. InsideTax, 17, 8-17. 
Devos, K. (2012). The impact of tax professional upon the compliance behavior of Australian individual taxpayer. Revenue Law Journal, 22(1), 1-26.

Ditto, P. H., \& Lopez, D. F. (1992). Motivated scepticism: use of differential decision criteria for the preferred and nonpreferred conclusion. Journal of Personality and Social Psychology, 63, 568-584. https://doi.org/10.1037/0022-3514.63.4.568

Ditto, P. H., Munro, G. D., Apanovitch, A. M., Scepansky, J. A., \& Lockhart, L. K. (2003). Spontaneous skepticism: the interplay of motivation and expectation in responses to favorable and unfavorable medical diagnoses. Personality and Social Psychology Bulletin, 29, 1120-1132. https://doi.org/10.1177/0146167203254536

Erdelyi, M. H. (1974). A new look at the new look: Perceptual defence and vigilance. Psychological Review, 81(1), 1-25. https://doi.org/10.1037/h0035852

Feldman, N., Goldin, J., \& Homonoff, T. (2018). Raising the stakes: Experimental evidence of the endogeneity of taxpayers mistakes. National Tax Journal, 17(2), 201-230.

https://doi.org/10.17310/ntj.2018.2.01

Festinger, L. (1957). A theory of cognitive dissonance. Stanford, CA: Stanford University Press.

Hales, J. W. (2002). Understanding bias and dispersion in forecasts: The role of motivated reasoning (Working paper). Cornell University. https://doi.org/10.2139/ssrn.360980

Hansen, V. J., \& White, R. A. (2012). An investigation of the impact of tax preparer penalty provision on taxpayers aggressiveness. The Journal of American Taxation Association, 34(1), 137-165. https://doi.org/10.2308/atax-10183

Heider, F. (1958). The psychology of interpersonal relations. New York: Wiley. https://doi.org/10.1037/10628-000

Jiwo, P., \& Zulaikha. (2016). Analisis faktor-faktor individual dalam pengambilan keputusan etis oleh konsultan pajak. Paper presented at the Proceeding of The XVI National Accounting Symsposium, Bandar Lampung.

Kadous, K., \& Magro, A. M. (2001). The effects of exposure to practice risk on tax professionals' judgments and recommendations. Contemporary Accounting Research, 18(3), 451-475. https://doi.org/10.1506/TF76-653L-R36N-13YP

Kadous, K., Magro, A., \& Spilker, B. (2008). Do the effects of client preference on accounting professionals' information search persist with high practice risk? The Accounting Review, 83(1), 133-156. https://doi.org/10.2308/accr.2008.83.1.133

Kahle, J. B., \& White, R. A. (2004). Tax professional decision biases: The effects of initial beliefs and client preference. The Journal of the American Taxation Association, 26 (s-1), 1-29. https://doi.org/10.2308/jata.2004.26.s-1.1

Kaklauskas, A., Zavadskas, E. K., \& Budzevičienè, R. (2009). Web-based model of multiple criteria ethical decision making for the ethical behavior of students. Journal of Business Economics and Management, 10(1), 71-84. https://doi.org/10.3846/1611-1699.2009.10.71-84

Kerr, N. L. (1995). Norms in social dilemmas. In D. Schroeder (Ed.), Social dilemmas: Social psychological perspectives (pp. 31-47). New York: Pergamon Press.

Koch, C., \& Salterio, S. E. (2015). Effects of client pressure and audit firm management control systems on auditor judgments (Working paper). https://doi.org/10.2139/ssrn.2572486

Koch, C., \& Salterio, S. E. (2017). The effect of auditor affinity for the client and perceived client pressure on auditor proposed adjustment. Accounting Review, 92(5), 117-142. https://doi.org/10.2308/accr-51703

Kunda, Z. (1990). The case for motivated reasoning. Psychological Bulletin, 108(3), 480-498. https://doi.org/10.1037//0033-2909.108.3.480 
Lee, S. Y. (2015). Factors affecting audit revenues. Advanced Science and Technology Letters, 102, 6-9. https://doi.org/10.14257/astl.2015.102.02

Libby, R., Bloomfield, R., \& Nelson, M. W. (2002). Experimental research in financial accounting. Accounting, Organizations and Society, 27, 775-811. https://doi.org/10.1016/S0361-3682(01)00011-3

Miller, D. T., \& Ross, M. (1975). Self-serving biases in attribution of causality: Fact or fiction? Psychological Bulletin, 82, 213-225. https://doi.org/10.1037/h0076486

Nelson, M. W. (2003). Behavioral evidence on the effects of principles- and rules-based standards. Accounting Horizons, 17(1), 91-104. https://doi.org/10.2308/acch.2003.17.1.91

Nickerson, R. S. (1998). Confirmation bias: A ubiquitous phenomenon in many guises. Review of General Psychology, 2(2), 175-220. https://doi.org/10.1037/1089-2680.2.2.175

Nisbett, R., \& Ross, L. (1980). Human inference: strategies and shortcomings of social judgment. New Jersey: Prentice Hall.

Pennington, R., Schafer, J. K., \& Pinsker, R. (2017). Do auditor advocacy attitues impede audit objectivity? Journal of Accounting, Auditing \& Finance, 32(1), 136-151.

https://doi.org/10.1177/0148558X16641862

Rose, J. M., \& Wolfe, C. J. (2000). The effects of system design alternatives on the acquisition of tax knowledge from a computerized tax decision aid. Accounting. Organization and Society, 25, 285306. https://doi.org/10.1016/S0361-3682(99)00048-3

The Republic of Indonesia. (2014). Minister of Finance Decree No. 111/2014 concerning tax consultants. Retrieved from https://www.ikpi.or.id/sites/default/files/peraturan_pajak/pmk111214.pdf

Saee, J. (2005). Societal ethics and legal system facing contemporary marketing strategies: an Australian insight. Journal of Business Economics and Management, 6(4), 189-197.

https://doi.org/10.3846/16111699.2005.9636108

Saputra, K. E., \& Adam, H. (2016). Pemahaman pegawai Direktorat Jenderal Pajak dan konsultan pajak tentang perilaku wajib pajak: sebuah studi fenomenologi. Paper presented at the Proceeding of the XVI National Accounting Symposium, Bandar Lampung.

Schwartz, S. H. (1977). Normative in fluences on altruism. In L. Berkowitz (Ed.), Advances in experimental social psychology (Vol. 10, pp. 221-279). New York: Academic Press.

https://doi.org/10.1016/S0065-2601(08)60358-5

Simone, L. D., Sansing, R. C., \& Seidman, J. K. (2008). When is enhanced relationship tax compliance program mutually beneficial? The Accounting Review, 88(6), 1971-1991. https://doi.org/10.2308/accr-50525

Stephenson, T. (2010). Measuring taxpayers' motivation to hire tax preparers: the development of a for-construct scale. Advances in Taxation, 19, 95-121. https://doi.org/10.1108/S1058-7497(2010)0000019006

Suddaby, R., Gendron, Y., \& Lam, H. (2009). The organizational context of professionalism in accounting. Accounting, Organizations \& Society, 34(3/4), 409-427. https://doi.org/10.1016/j.aos.2009.01.007

Wason, P. C. (1960). On the failure to eliminate hypotheses in a conceptual task. Quarterly Journal of Experimental Psychology, 12, 129-140. https://doi.org/10.1080/17470216008416717

Wenzel, M. (2004). An analysis of norm processes in tax compliance. Journal of Economic Psychology, 25, 213-228. https://doi.org/10.1016/S0167-4870(02)00168-X

Wheeler, P. R., \& Arunachalam, V. (2008). The effects of decision aid design on the information search strategies and confirmation bias of tax professionals. Behavioral Research in Accounting, 20(1), 131145. https://doi.org/10.2308/bria.2008.20.1.131 